\title{
Topotactic fluorination of strontium iron oxide thin films using polyvinylidene fluoride
}

Cite this: J. Mater. Chem. C, 2014, 2 , 5350

Received 20th March 2014 Accepted 24th April 2014

DOI: $10.1039 / \mathrm{c} 4 \mathrm{tc00558a}$

www.rsc.org/MaterialsC

\author{
T. Katayama, ${ }^{a}$ A. Chikamatsu, ${ }^{\text {*ab }}$ Y. Hirose, ${ }^{a b c}$ R. Takagi, ${ }^{a}$ H. Kamisaka, ${ }^{\text {ab }}$ T. Fukumura ${ }^{a b}$ \\ and T. Hasegawa ${ }^{\text {abc }}$
}

We report herein the topotactic fluorination of $\mathrm{SrFeO}_{3-\delta}$ thin films $(\delta \sim 0,0.5,1)$ with polyvinylidene fluoride (PVDF). $\mathrm{SrFeO}_{3-x} \mathrm{~F}_{x}$ epitaxial thin films were obtained by fluorination at $150-270{ }^{\circ} \mathrm{C}$, which is substantially lower than the reaction temperature for polycrystalline bulk samples prepared with PVDF. The fluorine content $(x)$ of the film was widely varied by controlling the PVDF-treatment temperature and/or the amount of oxygen vacancies in the precursor film. The higher reactivity of the $\mathrm{SrFeO}_{2}$ and $\mathrm{SrFeO}_{2.5}$ thin films can be reasonably explained by a fluorine-diffusion mechanism via oxygen vacancies.

\section{Introduction}

Since the discovery of superconductivity (transition temperature of $T_{\mathrm{c}}=46 \mathrm{~K}$ ) in non-ordinary oxyfluorides $\mathrm{Sr}_{2} \mathrm{CuO}_{2} \mathrm{~F}_{2+x}$, the replacement of $\mathrm{O}^{2-}$ by $\mathrm{F}^{-}$in transition-metal oxides has attracted a great deal of attention as a chemical technique that can considerably modify the electronic properties of their mother compounds. Among these compounds, fluorinesubstituted iron oxides have been a subject of intense study owing to their unique magnetic properties. For example, the partially F-substituted hexagonal perovskite, $15 \mathrm{R}-\mathrm{BaFeF}_{0.2} \mathrm{O}_{2.42}$, shows drastically enhanced antiferromagnetic ordering with a Néel temperature $\left(T_{\mathrm{N}}\right)$ of $\approx 700 \mathrm{~K}$, which is close to the highest values ever reported for iron oxides. ${ }^{2}$ Such a high $T_{\mathrm{N}}$ can be explained by local changes of the $\mathrm{Fe}-\mathrm{X}-\mathrm{Fe}(\mathrm{X}=\mathrm{O}, \mathrm{F})$ bond angle, bond length, as well as chemical reduction of iron.

Iron oxyfluorides are often metastable and decompose at higher temperatures, making the development of low-temperature synthetic routes desirable. One promising method is a topotactic reaction employing a fluorination agent, polyvinylidene fluoride (PVDF), which is stable in air, and has a melting point of $\sim 170{ }^{\circ} \mathrm{C} .{ }^{3}$ Fluorination using PVDF is advantageous for obtaining phase-pure oxyfluorides without metal fluoride impurities, which are frequently formed by other fluorinating agents such as $\mathrm{F}_{2}$ gas and $\mathrm{NH}_{4} \mathrm{~F}$. $^{3}$ In addition, $\mathrm{PVDF}$ is a non-oxidizing reagent, ${ }^{4}$ in contrast to highly oxidizing $\mathrm{F}_{2}$ gas; therefore, metal ions are not oxidized during the fluorination reaction, but rather, reduced. Indeed, PVDF-promoted

${ }^{a}$ Department of Chemistry, The University of Tokyo, Bunkyo-ku, Tokyo 113-0033, Japan. E-mail: chikamatsu@chem.s.u-tokyo.ac.jp; Fax: +81-3-5841-4603; Tel: +81-35841-4603

${ }^{b}$ CREST, Japan Science and Technology Agency (JST), Bunkyo-ku, Tokyo 113-0033, Japan

${ }^{c}$ Kanagawa Academy of Science and Technology (KAST), Kawasaki, Kanagawa 2130012, Japan fluorination has been widely used to synthesize various species of iron oxyfluorides accompanied by a reduction in the $\mathrm{Fe}$ oxidation state. ${ }^{-13}$ For example, a perovskite oxide $\mathrm{SrFeO}_{3-\delta}$ (with $\mathrm{Fe}^{3+/ 4+}$ ) can be transformed to $\mathrm{SrFeO}_{2} \mathrm{~F}$ (with $\mathrm{Fe}^{3+}$ ) by annealing with PVDF. ${ }^{5}$

It is expected that the reactivity of thin-film samples with PVDF should be much higher than that of bulk samples because thin films have larger surface areas and smaller volumes than bulk samples. More recently, the fluorination technique using PVDF was applied to $\mathrm{SrFeO}_{3-\delta}$ thin films, where a PVDF solution was spin-coated on the film and the film/polymer bilayer was annealed at $600{ }^{\circ} \mathrm{C}$, though the $\mathrm{SrFeO}_{3-\alpha} \mathrm{F}_{\gamma}$ films thus obtained had relatively low fluorine contents $(\gamma<1)$ despite higher synthesis temperature than that for bulk $\mathrm{SrFeO}_{2} \mathrm{~F} \cdot{ }^{14}$ Another important factor governing the reactivity of thin-film samples with PVDF is the amount of oxygen vacancies in the precursor oxides, because the incorporation of fluorine ions into the oxygen-vacancy sites would be faster than the actual replacement of oxygen by fluorine. In fact, bulk $\mathrm{SrFeO}_{2} \mathrm{~F}$ can be obtained at $150{ }^{\circ} \mathrm{C}$ by fluorinating infinite-layer $\mathrm{SrFeO}_{2}$ with $\mathrm{XeF}_{2} \cdot{ }^{15}$ Herein, we performed topotactic fluorine doping of $\operatorname{SrFeO}_{x}(2 \leq x<3)$ thin films using PVDF. As a result, we succeeded in fabricating $\mathrm{SrFeO}_{3-x} \mathrm{~F}_{x}$ epitaxial thin films, in which the fluorine content $(x)$ was controllable over a wide range $(0.8 \leq x \leq \sim 1.5)$ by means of the heat-treatment temperature. The fluorination reaction was conducted at $150-270{ }^{\circ} \mathrm{C}$, which was much lower than the $400{ }^{\circ} \mathrm{C}$ reaction temperature reported for the bulk. We also found that the value of $x$ is dependent on the amount of oxygen vacancies present in the precursor $\mathrm{SrFeO}_{x}$ film.

\section{Experimental section}

\section{Synthesis}

Three types of precursor $\mathrm{SrFeO}_{x}$ films with different oxygen contents $\left(x \approx 2,2.5\right.$, and 3 ) were prepared. Precursor $\mathrm{SrFeO}_{2.5}$ 
films were grown on $\mathrm{SrTiO}_{3}$ (001) (STO, Shinkosha Co.) substrates by a pulsed-laser deposition (PLD) technique, with a $\mathrm{SrFeO}_{3-\delta}$ ceramic pellet $(20 \mathrm{~mm}$ in diameter and $5 \mathrm{~mm}$ in thickness, TOSHIMA Manufacturing Co.) used as a PLD target. The fourth harmonic of a Nd-YAG laser (wavelength $\lambda=266 \mathrm{~nm}$ ) with an energy of $0.3 \mathrm{~J} \mathrm{~cm}^{-2}$ per shot and a repetition rate of $10 / 3 \mathrm{~Hz}$ was employed for ablation. The substrate temperature and oxygen partial pressure were kept at $700{ }^{\circ} \mathrm{C}$ and $7 \times 10^{-5}$ mbar, respectively, during each deposition run, and coherent growth of the precursor $\mathrm{SrFeO}_{2.5}$ films on STO (001) substrates was confirmed. Oxidized $\operatorname{SrFeO}_{x}(x \approx 3)$ films with perovskite structure were fabricated by annealing $\mathrm{SrFeO}_{2.5}$ films at $700{ }^{\circ} \mathrm{C}$ in air for $2 \mathrm{~h}$. Additional reduced $\operatorname{SrFeO}_{x}(x \approx 2)$ films with infinite-layer structures were obtained by heating $\mathrm{SrFeO}_{2.5}$ films with $\mathrm{CaH}_{2}$ (Wako Pure Chemical Industries, Ltd.) at $280{ }^{\circ} \mathrm{C}$ for $24 \mathrm{~h}$ in evacuated Pyrex tubes as described in ref. 16 .

The obtained precursor $\operatorname{SrFeO}_{x}(x \approx 2,2.5$, and 3) films were further subjected to fluorination with $0.1 \mathrm{~g}$ of PVDF (Fluorochem Ltd.) at temperatures $\left(T_{\mathrm{f}}\right)$ ranging from 100 to $450{ }^{\circ} \mathrm{C}$ for $24 \mathrm{~h}$ under an Ar gas flow of $70 \mathrm{~cm}^{3} \mathrm{~min}^{-1}$ (with the films covered by $\mathrm{Al}$ foil so as not to contact with PVDF directly). Typical film thickness, as measured using a stylus surface profiler, was $\sim 80 \mathrm{~nm}$.

\section{Characterization}

Crystal structures of the $\mathrm{SrFeO}_{3-x} \mathrm{~F}_{x}$ films were obtained with an $\mathrm{X}$-ray diffractometer employing $\mathrm{Cu}-\mathrm{K} \alpha$ radiation and a transmission electron microscope (TEM). The chemical composition of the films was analysed by energy dispersive X-ray spectrometry (EDS) equipped with a scanning electron microscope in which the electron accelerating voltage was set at $2.5 \mathrm{keV}$ to reduce the background signal from the substrate. The amount of fluorine was evaluated by nuclear reaction analysis (NRA) using the ${ }^{19} \mathrm{~F}(p, \alpha \gamma){ }^{16} \mathrm{O}$ resonant nuclear reaction at $902 \mathrm{keV}$. In NRA measurements, a $\mathrm{CaF}_{2}$ single crystal was used as a reference for fluorine. The EDS and NRA results included experimental errors of $\sim 20 \%$. The depth profiles of the chemical compositions were evaluated by X-ray photoemission spectroscopy (XPS) with $\mathrm{Ar}^{+}$-ion sputtering. The core levels of iron were also observed by XPS. The surface morphology was characterized by atomic force microscopy (AFM).

\section{Results and discussion}

\section{Crystal structure analysis}

Fig. 1(a) shows the $2 \theta-\theta$ X-ray diffraction (XRD) patterns of films obtained by fluorination of the $\mathrm{SrFeO}_{2.5}$ precursor film at $T_{\mathrm{f}}=$ $100-450{ }^{\circ} \mathrm{C}$ for $24 \mathrm{~h}$. The XRD pattern of the $\mathrm{SrFeO}_{2.5}$ precursor film has also been included in the figure for comparison. The film treated with PVDF at $100{ }^{\circ} \mathrm{C}$ showed a diffraction peak at $2 \theta$ $\approx 45.8^{\circ}$, corresponding to the (002) reflection of the $\mathrm{SrFeO}_{2.5}$ structure, which means that PVDF did not react with the $\mathrm{SrFeO}_{2.5}$ film below $100{ }^{\circ} \mathrm{C}$. The films fluorinated at $150-270{ }^{\circ} \mathrm{C}$ exhibited only the (002) diffraction peaks of the perovskite structure, indicating that $\mathrm{SrFeO}_{3-x} \mathrm{~F}_{x}$ can be obtained at 150$270{ }^{\circ} \mathrm{C}$. Additionally, the position of the (002) peak was shifted
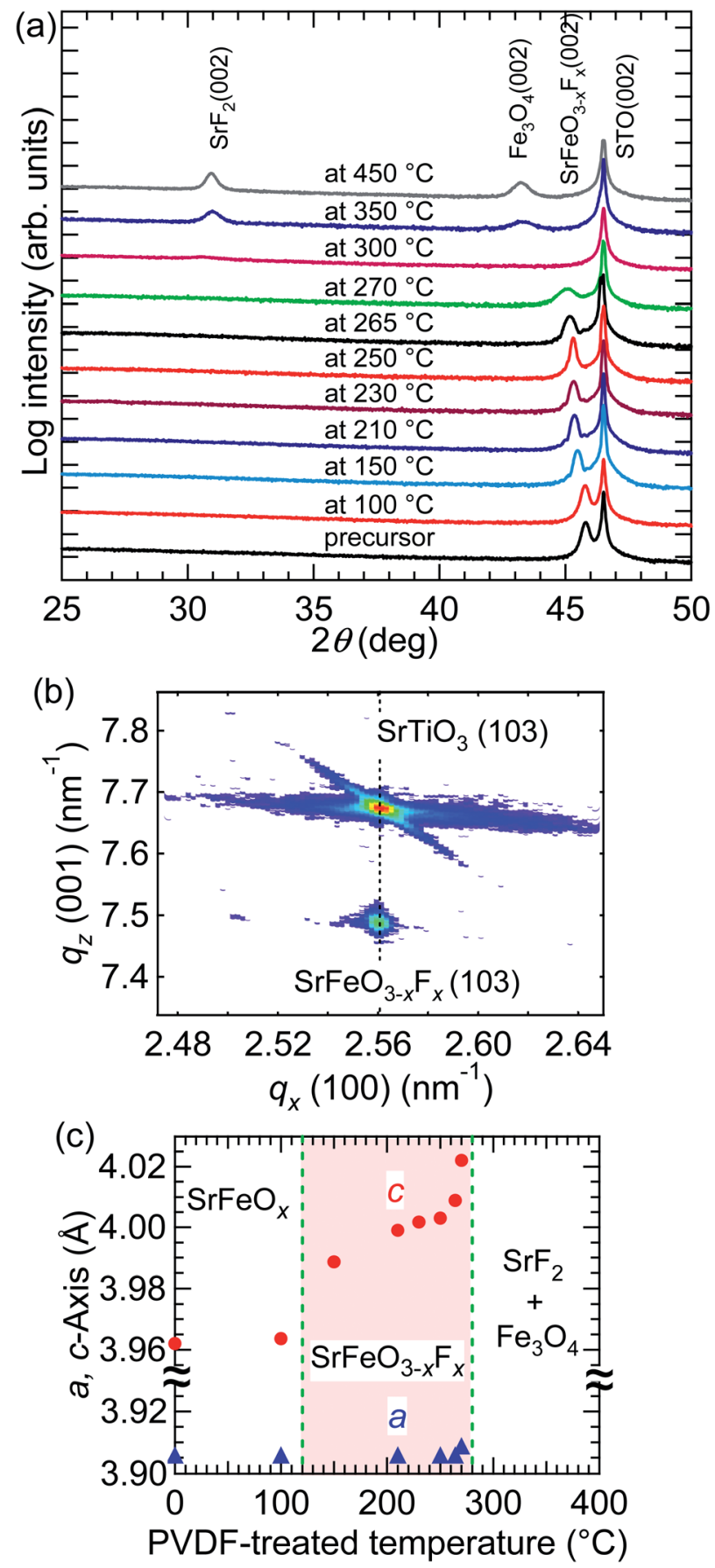

Fig. 1 (a) $2 \theta-\theta \mathrm{X}$-ray diffraction patterns of the $\mathrm{SrFeO}_{2.5}$ precursor film and films fluorinated at $100-450{ }^{\circ} \mathrm{C}$ with PVDF for $24 \mathrm{~h}$. (b) Logarithmic contour mapping in reciprocal space for asymmetric (103) peaks of the $\mathrm{SrFeO}_{3-x} \mathrm{~F}_{x}$ film on the $\mathrm{SrTiO}_{3}$ substrate fluorinated at $250{ }^{\circ} \mathrm{C}$. (c) Lengths of $a-$ and $c$-axes of $\mathrm{SrFeO}_{3-x} \mathrm{~F}_{x}$ films as a function of fluorination temperature.

to the lower-angle side (from $45.5^{\circ}$ to $45.1^{\circ}$ ) on increasing $T_{\mathrm{f}}$ from 150 to $270{ }^{\circ} \mathrm{C}$. At $300{ }^{\circ} \mathrm{C}$, the diffraction peak of perovskite $\mathrm{SrFeO}_{3-x} \mathrm{~F}_{x}$ disappeared, and a peak assignable to $\mathrm{SrF}_{2}(002)$ appeared. Above $350{ }^{\circ} \mathrm{C}$, the peaks corresponding to $\mathrm{SrF}_{2}(002)$ and $\mathrm{Fe}_{3} \mathrm{O}_{4}$ (002) evolved, reflecting the complete decomposition of perovskite $\mathrm{SrFeO}_{3-x} \mathrm{~F}_{x}$ into $\mathrm{SrF}_{2}$ and $\mathrm{Fe}_{3} \mathrm{O}_{4}$. 
Fig. 1(b) shows an XRD reciprocal space map for asymmetric (103) diffraction of the $\mathrm{SrFeO}_{3-x} \mathrm{~F}_{x}$ film fluorinated at $250{ }^{\circ} \mathrm{C}$. Notably, the $q_{x}$ value of the $\mathrm{SrFeO}_{3-x} \mathrm{~F}_{x}$ (103) peak coincides with that of STO (103). This implies that the $a$-axis of the $\mathrm{SrFeO}_{3-x} \mathrm{~F}_{x}$ film was completely locked to the STO lattice, even after treatment with PVDF. In other words, the perovskite-like cation network was maintained during the topotactic fluorination reaction promoted by PVDF.

Fig. 1(c) shows the plots of lengths of the $a$-and $c$-axes for the $\mathrm{SrFeO}_{3-x} \mathrm{~F}_{x}$ films as a function of $T_{\mathrm{f}}$. The $c$-axis length increased from 3.989 to $4.022 \AA$ upon increasing $T_{\mathrm{f}}$ from 150 to $270{ }^{\circ} \mathrm{C}$ in a nonlinear manner, whereas the $a$-axis length was essentially independent of $T_{\mathrm{f}}$. In the case of bulk $\mathrm{SrFeO}_{2} \mathrm{~F}$, it was reported that the cell volume was greatly increased upon fluorination of precursor $\mathrm{SrFeO}_{3-\delta}$ because of the simultaneous occurrence of fluorine insertion and substitution. ${ }^{5,17}$ Therefore, in this case, the increase in the $c$-axis length suggests that similar fluorine insertion and substitution reactions take place.

Fig. 2(a) shows a wide-view cross-sectional TEM image of the $\mathrm{SrFeO}_{3-x} \mathrm{~F}_{x}$ film fluorinated at $270{ }^{\circ} \mathrm{C}$. Neither segregated impurities nor amorphous phases were recognized from the TEM observations. Fig. 2(b) is a magnified view of the same image. The image clearly indicates a tetragonal perovskite structure with lattice constants of $a \sim 3.9 \AA$ and $c \sim 4.0 \AA$, which is consistent with those obtained from XRD $(a=3.908 \AA$ and $c=4.022 \AA$ ).

\section{Compositional analysis}

To verify fluorine doping and to investigate the relationship between the doped fluorine content and $T_{\mathrm{f}}$, EDS measurements were performed for $\mathrm{O} \mathrm{K} \alpha, \mathrm{F} \mathrm{K} \alpha$, and Fe L $\alpha$. Fig. 3(a) depicts the EDS spectra near the $\mathrm{O} \mathrm{K} \alpha$ and $\mathrm{F} \mathrm{K} \alpha$ peaks of the $\mathrm{SrFeO}_{2.5}$ precursor and $\mathrm{SrFeO}_{3-x} \mathrm{~F}_{x}$ films fluorinated at 150, 250, and $270{ }^{\circ} \mathrm{C}$, where the spectral intensity was normalized by the area of the Fe $\mathrm{L} \alpha$ peak. As seen in the figure, the peak area of $\mathrm{F} \mathrm{K} \alpha$ increased with increase in $T_{\mathrm{f}}$, while that of $\mathrm{O} \mathrm{K} \alpha$ showed a
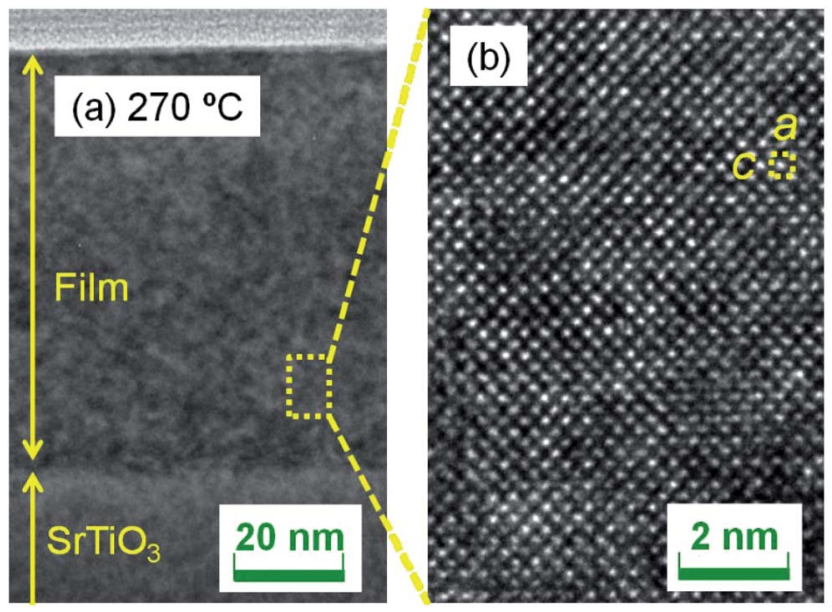

Fig. 2 Cross-sectional transition electron microscopy images of the $\mathrm{SrFeO}_{3-x} \mathrm{~F}_{x}$ film fluorinated at $270{ }^{\circ} \mathrm{C}$ with (a) a wide-range view and (b) a magnified view.
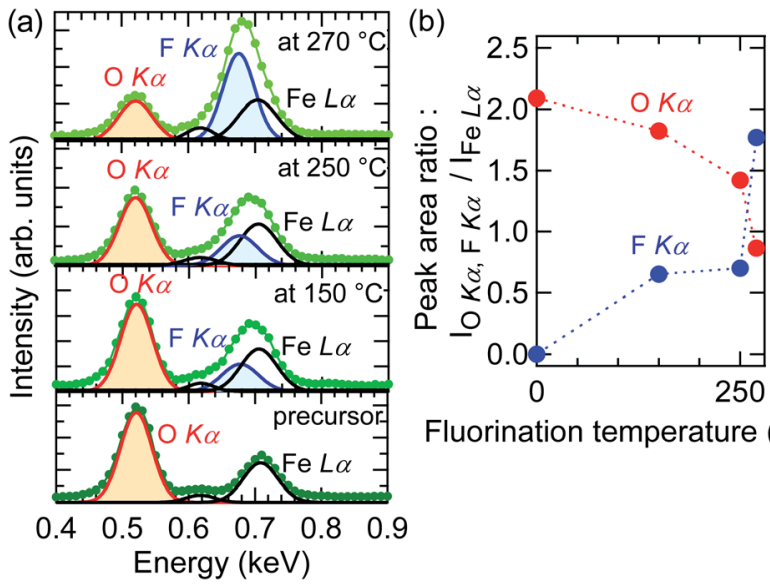

Fluorination temperature $\left({ }^{\circ} \mathrm{C}\right)$

Fig. 3 Energy dispersive $X$-ray spectra (EDS) near (a) O K $\alpha, F K \alpha$, and $\mathrm{Fe}$ $\mathrm{L} \alpha$ peaks of the $\mathrm{SrFeO}_{2.5}$ precursor film and $\mathrm{SrFeO}_{3-x} \mathrm{~F}_{x}$ films fluorinated at 150, 250, and $270{ }^{\circ} \mathrm{C}$. (b) EDS peak area of $\mathrm{F} K \alpha$ and $\mathrm{O} K \alpha$ as a function of fluorination temperature.

tendency to decrease. Fig. 3(b) shows the plots of the areas of the F K $\alpha$ and O K $\alpha$ peaks, $S_{\mathrm{F}}$ and $S_{\mathrm{O}}$, respectively, against $T_{\mathrm{f}}$. The $S_{\mathrm{F}} / S_{\mathrm{O}}$ ratio of the film fluorinated at $250{ }^{\circ} \mathrm{C}$ is $1: 2$, whereas that of the film fluorinated at $270{ }^{\circ} \mathrm{C}$ is enhanced to $2: 1$. This implies that the fluorine content of the $\mathrm{SrFeO}_{3-x} \mathrm{~F}_{x}$ films can be controlled by $T_{\mathrm{f}}$.

NRA measurements were conducted so as to quantitatively determine the fluorine content of the films. Fig. 4(a) shows the NRA spectrum of the $\mathrm{SrFeO}_{3-x} \mathrm{~F}_{x}$ film fluorinated at $250{ }^{\circ} \mathrm{C}$. The $\gamma$-ray emitted by the nuclear reaction of ${ }^{19} \mathrm{~F}(p, \alpha \gamma){ }^{16} \mathrm{O}$ was clearly observed in the $\mathrm{SrFeO}_{3-x} \mathrm{~F}_{x}$ film, and the $x$ value was determined to be $0.92 \pm 0.18$. Fig. 4 (b) shows the correlation between the $c$-axis length and $x$ values in $\mathrm{SrFeO}_{3-x} \mathrm{~F}_{x}$, where the $x$ values were evaluated from EDS and NRA measurements independently, referred to as $x$ (EDS) and $x$ (NRA), respectively. For the evaluation of $x$ (EDS), the relationship $x=3 \times S_{\mathrm{F}} /\left(S_{\mathrm{F}}+a \times S_{\mathrm{O}}\right)$ was used in an assumption of $\mathrm{O}: \mathrm{F}=3-x: x$, where the relative sensitivity factor $(a)$ was estimated to be 0.989 based on a Monte Carlo simulation of electron trajectory in solids. ${ }^{18}$ As seen in Fig. 4(b), both $x$ (EDS) and $x$ (NRA) are in good agreement with each other, which indicates that the assumption mentioned above $(\mathrm{O}: \mathrm{F}=(3-x): x)$ is reasonable, although we cannot deny the possibility that a certain amount of oxygen vacancies remains in the film (in other words, the doped fluorine atoms were substituted for the oxygen sites of the perovskite lattice). Notably, the $c$-axis length of the $\mathrm{SrFeO}_{3-x} \mathrm{~F}_{x}$ film increased as the value of $x$ increased, despite the fact that $\mathrm{F}^{-}$has a smaller ionic radius than $\mathrm{O}^{2-}$. This can be rationalized by taking the chemical reduction of the Fe ions into consideration. The shrinkage of cell volume associated with $\mathrm{F}^{-}$substitution is overwhelmed by cell expansion upon the reduction of $\mathrm{Fe}$ ions. ${ }^{5,17}$ The $x$ value of the $\mathrm{SrFeO}_{3-x} \mathrm{~F}_{x}$ film fluorinated at $270{ }^{\circ} \mathrm{C}$ was $\sim 2$, which is twice that of bulk $\mathrm{SrFeO}_{2} \mathrm{~F}$, though we cannot deny the possibility that the fluorine contents were overestimated because carbon impurities on the surface may adsorb fluorine ions during the PVDF treatment. 

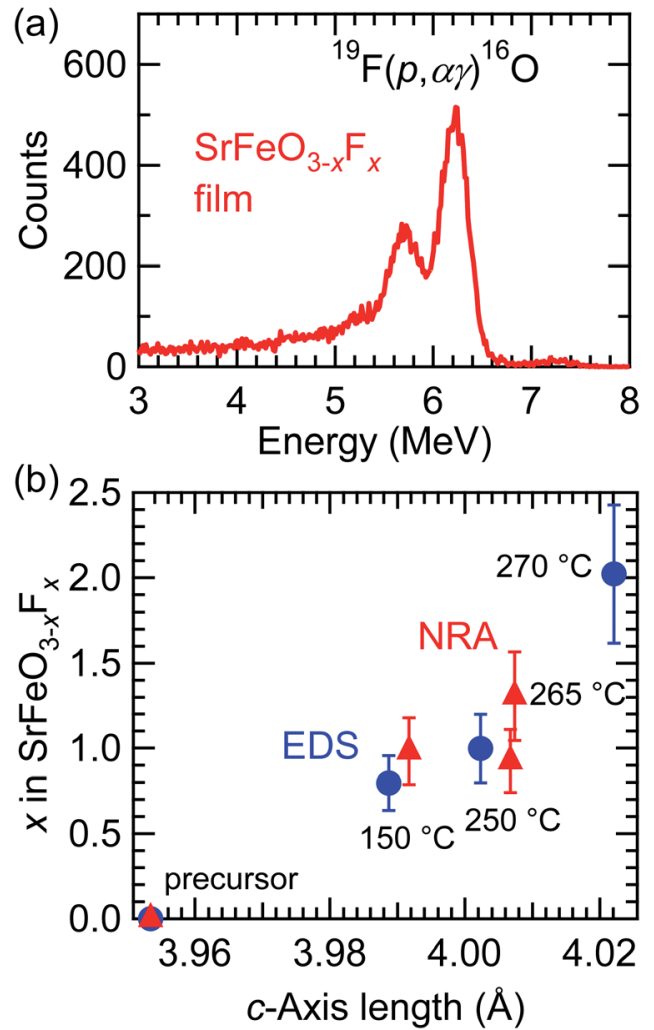

Fig. 4 (a) Nuclear reaction analysis (NRA) spectra of the $\mathrm{SrFeO}_{3-x} \mathrm{~F}_{x}$ film fluorinated at $250{ }^{\circ} \mathrm{C}$. (b) $\mathrm{C}$-Axis length dependence of $x$ in the $\mathrm{SrFeO}_{3-x} \mathrm{~F}_{x}$ film, estimated from energy dispersive $\mathrm{X}$-ray spectra (EDS) and NRA measurements. Different samples were used for NRA and EDS measurements.

Because fluorination proceeds at the film surface, the population of fluorine ions is potentially higher closer to the surface. Fig. 5 shows the fluorine depth profile of the $\mathrm{SrFeO}_{3-x} \mathrm{~F}_{x}(x \approx 1)$ film obtained at $250{ }^{\circ} \mathrm{C}$, measured by XPS with $\mathrm{Ar}^{+}$-ion sputtering, where the peak area of $\mathrm{F} 1 \mathrm{~s}$ relative to that of $\mathrm{O} 1 \mathrm{~s}, A_{\mathrm{F}} / A_{\mathrm{O}}$, at the surface $(0 \mathrm{~nm})$ was set to 1 . Near the surface (0-15 nm) the $A_{\mathrm{F}} / A_{\mathrm{O}}$ decreased with increasing depth, reaching $\sim 0.8$ at $15 \mathrm{~nm}$, suggesting the presence of impurities containing fluorine on the surface. The $A_{\mathrm{F}} / A_{\mathrm{O}}$ value was virtually constant at $15-80 \mathrm{~nm}$, and slightly increased near the interface of the film and the substrate. These results suggest that fluorine ions diffused not only in the vicinity of the surface, but also over the entire film. On the other hand, in the STO substrate region (>90 nm), fluorine was not detected, indicating that the diffusion of fluorine into the STO substrate is negligible.

\section{Valence of iron and surface morphology}

Fig. 6 depicts the Fe 2p core-level XPS spectra of the $\mathrm{SrFeO}_{3-x} \mathrm{~F}_{x}$ films fluorinated at 150,250 , and $270{ }^{\circ} \mathrm{C}$. Each spectrum showed $\mathrm{Fe} 2 \mathrm{p}_{3 / 2}$ and $2 \mathrm{p}_{1 / 2}$ peaks, and a satellite peak located between the Fe $2 p_{1 / 2}-\mathrm{Fe} 2 \mathrm{p}_{3 / 2}$ doublet. Notably, the locations of the satellite peaks, which are known to be very sensitive to the oxidation state of Fe, differ from one sample to another. The satellite peaks in the $\mathrm{SrFeO}_{3-x} \mathrm{~F}_{x}$ films fluorinated at 150 and

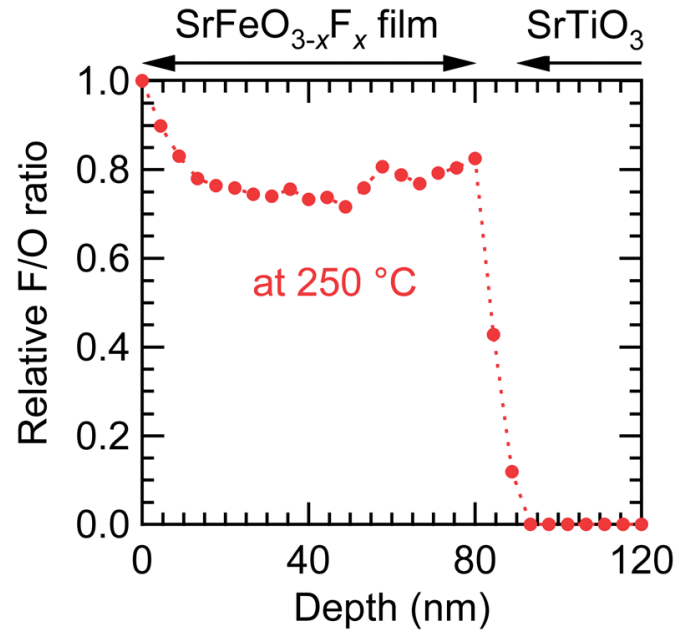

Fig. 5 Fluorine depth profile of the $\mathrm{SrFeO}_{3-x} \mathrm{~F}_{x}(x \approx 1)$ film fluorinated at $250{ }^{\circ} \mathrm{C}$, obtained from the $\mathrm{SrFeO}_{2.5}$ precursor film, measured by $\mathrm{X}$ ray photoemission spectroscopy with $\mathrm{Ar}^{+}$-ion sputtering.

$250{ }^{\circ} \mathrm{C}$ were located at an $E_{\mathrm{b}}$ of $\sim 719$ and $\sim 718 \mathrm{eV}$, respectively, which are equivalent to the peak in $\mathrm{LaFeO}_{3}$ with $\mathrm{Fe}^{3+}\left(E_{\mathrm{b}}=\right.$ $718.7 \mathrm{eV}) .{ }^{19}$ That is, the valences of the Fe ions in the films are almost trivalent. Meanwhile, the satellite peak of the film fluorinated at $270{ }^{\circ} \mathrm{C}$ was located at an $E_{\mathrm{b}}$ of $712-719 \mathrm{eV}$, between the doublet peaks, suggesting that the $\mathrm{Fe}$ ion has a mixed valence state of $\mathrm{Fe}^{2+} / \mathrm{Fe}^{3+} \cdot{ }^{20}$ The $\mathrm{Fe}^{2+} / \mathrm{Fe}^{3+}$ ratio was further evaluated by comparing the XPS data of the $\mathrm{SrFeO}_{3-x} \mathrm{~F}_{x}$ film fluorinated at $270{ }^{\circ} \mathrm{C}$ and the $\mathrm{SrFeO}_{2.5}$ film reported in ref. 21 . The area-intensity of the $\mathrm{Fe}^{3+}$ satellite peak relative to the $\mathrm{Fe} 2 \mathrm{p}_{3 / 2}$ main peak for the fluorinated film was approximately half that for the $\mathrm{SrFe}^{3+} \mathrm{O}_{2.5}$ film, implying that $\sim 50 \%$ of $\mathrm{Fe}$ exists as $\mathrm{Fe}^{3+}$

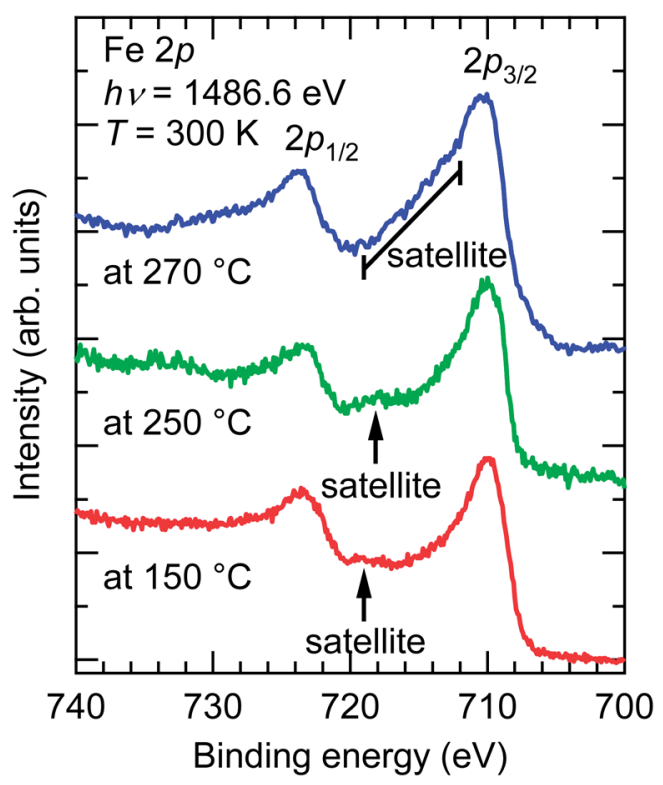

Fig. 6 Fe $2 \mathrm{p}$ core-level $\mathrm{X}$-ray photoemission spectra of $\mathrm{SrFeO}_{3-x} \mathrm{~F}_{x}$ films fluorinated at 150,250 , and $270{ }^{\circ} \mathrm{C}$, obtained from $\mathrm{SrFeO}_{2.5}$ precursor films. 
in the $\mathrm{SrFeO}_{3-x} \mathrm{~F}_{x}$ film. Thus, we can roughly deduce the fluorine content $(x)$ to be $x \approx 1.5$.

Fig. 7 shows the AFM images of the $\mathrm{SrFeO}_{2.5}$ precursor film and the $\mathrm{SrFeO}_{3-x} \mathrm{~F}_{x}$ films fluorinated at 250 and $270{ }^{\circ} \mathrm{C}$. The root mean square values of surface roughness were found to be 0.35 , 0.64 , and $0.81 \mathrm{~nm}$, respectively, indicating that the fluorination process does not cause severe surface roughening.

\section{Dependence on oxygen vacancies of precursor films}

The relationship between the fluorine content $(x)$ and oxygen vacancies in the precursor films is another important consideration. Fig. 8(a) and (b) compare the XRD patterns of the oxidized $\operatorname{SrFeO}_{x}(x \approx 3)$ and reduced $\operatorname{SrFeO}_{x}(x \approx 2)$ precursor films fluorinated at $150{ }^{\circ} \mathrm{C}$ for $24 \mathrm{~h}$. The oxidized and reduced precursor films show the (002) diffraction peaks of perovskitetype and infinite-layer structures with $c=3.835$ and $3.490 \AA$, respectively. The $c$-axis length of the oxidized $\operatorname{SrFeO}_{x}(x \approx 3)$ film is close to that of the strained $\mathrm{SrFeO}_{3}$ film on the STO substrate, 3.823 A. $^{22}$ After treatment with PVDF, the film prepared from the $\operatorname{SrFeO}_{x}(x \approx 3)$ precursor showed two (002) diffraction peaks corresponding to $c=3.871$ and $3.955 \AA$, whereas the film prepared from $\operatorname{SrFeO}_{x}(x \approx 2)$ exhibited one peak with $c=4.002 \AA$. Fig. 8(c) shows a plot of the $c$-axis lengths of the $\operatorname{SrFeO}_{x}(x \approx 2,2.5$, and 3$)$ precursor and fluorinated films. As seen in Fig. 8(c), the $c$-axis length of the film fluorinated at $150{ }^{\circ} \mathrm{C}$ becomes longer as the oxygen content in the precursor $\mathrm{SrFeO}_{x}$ film is decreased from $x \approx 3$ to 2 . Because the $c$-axis lengths of the fluorinated films reflect the fluorine content, this result suggests that precursor films containing more oxygen vacancies tend to incorporate more fluorine ions into the film.

To investigate the origin of the two (002) peaks, the fluorine and oxygen depth profiles of the $\mathrm{SrFeO}_{3-x} \mathrm{~F}_{x}$ film obtained from the oxidized $\operatorname{SrFeO}_{x}(x \approx 3)$ precursor were measured in detail (Fig. 9). As seen from the figure, the $A_{\mathrm{F}} / A_{\mathrm{O}} v s$. depth plot shows two plateaus: $\sim 0.8$ at $5-40 \mathrm{~nm}$ and $\sim 0.4$ at $40-80 \mathrm{~nm}$. These fluorine-rich and fluorine-poor regions correspond to the two (002) diffraction peaks at $2 \theta \approx 45.9^{\circ}$ and $47.0^{\circ}$, respectively (Fig. 8(a)). These results imply that the diffusion of fluorine ions is considerably slowed down as the concentration of oxygen vacancies decreases.
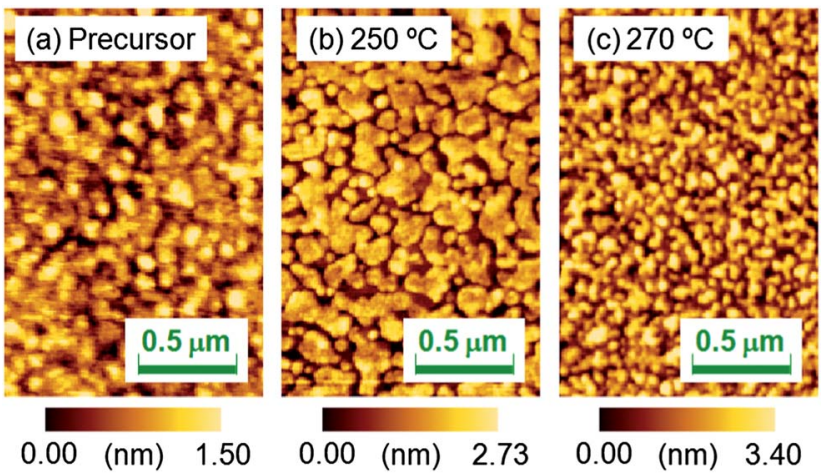

Fig. 7 Atomic force microscopy images of the (a) $\mathrm{SrFeO}_{2.5}$ precursor film and $\mathrm{SrFeO}_{3-x} \mathrm{~F}_{x}$ films fluorinated at (b) 250 and (c) $270{ }^{\circ} \mathrm{C}$.
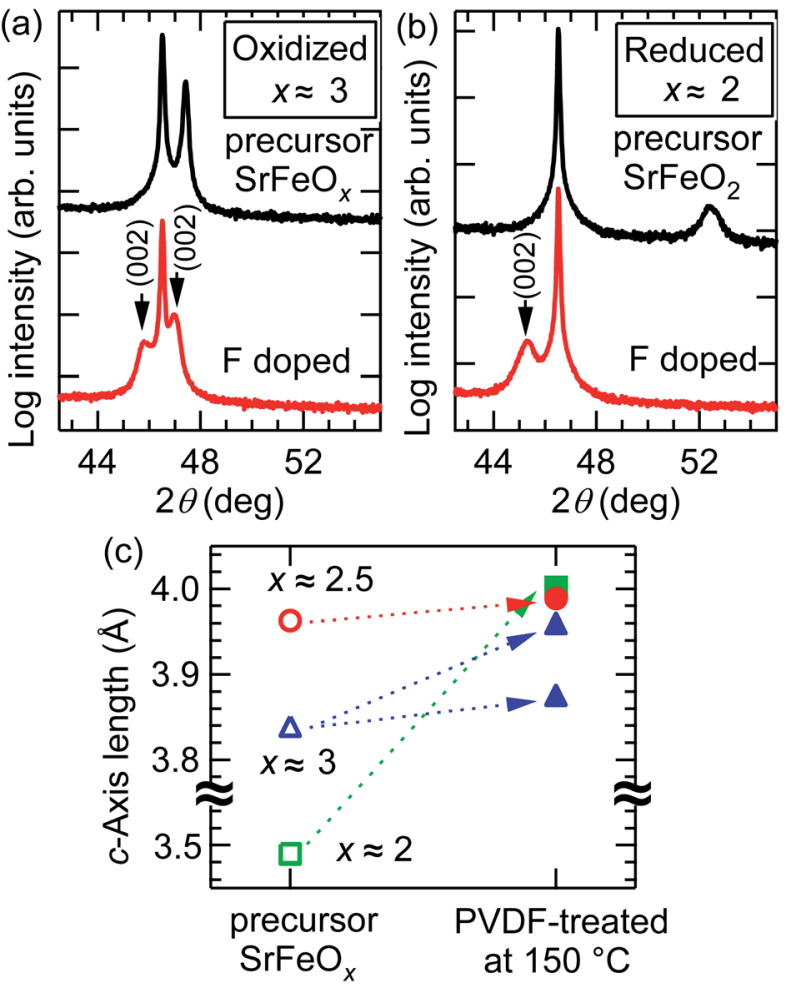

Fig. $8 X$-ray diffraction patterns of (a) oxidized $\operatorname{SrFeO}_{x}(x \approx 3)$ and (b) reduced $\mathrm{SrFeO}_{x}(x \approx 2)$ precursor films, and films fluorinated at $150{ }^{\circ} \mathrm{C}$ with PVDF for $24 \mathrm{~h}$. (c) c-Axis lengths of $\mathrm{SrFeO}_{x}(x \approx 2,2.5$, and 3) precursor and fluorinated films.

\section{Comparison with the diffusion mechanism}

As stated above, the $\mathrm{SrFeO}_{3-x} \mathrm{~F}_{x}$ films were obtained at much lower temperatures $\left(150-270{ }^{\circ} \mathrm{C}\right)$ than the bulk sample $\left(400{ }^{\circ} \mathrm{C}\right) .^{5}$ Now, we will discuss the difference in the reactivity between the thin film and bulk based on the diffusion equation. ${ }^{23}$ The fluorine ions were not diffused into the STO substrates (Fig. 5). In such a case, the relative fluorine concentration, $C(x)$, is given by eqn (1):

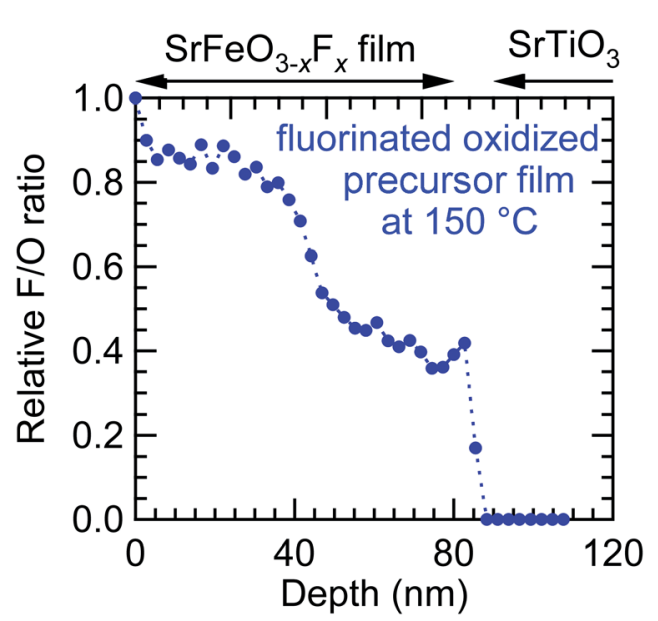

Fig. 9 Fluorine depth profile of the $\mathrm{SrFeO}_{3-x} \mathrm{~F}_{x}$ film fluorinated at $150{ }^{\circ} \mathrm{C}$ obtained from the oxidized $\mathrm{SrFeO}_{x}(x \approx 3)$ precursor film by $\mathrm{X}$-ray photoemission spectroscopy with $\mathrm{Ar}^{+}$-ion sputtering. 


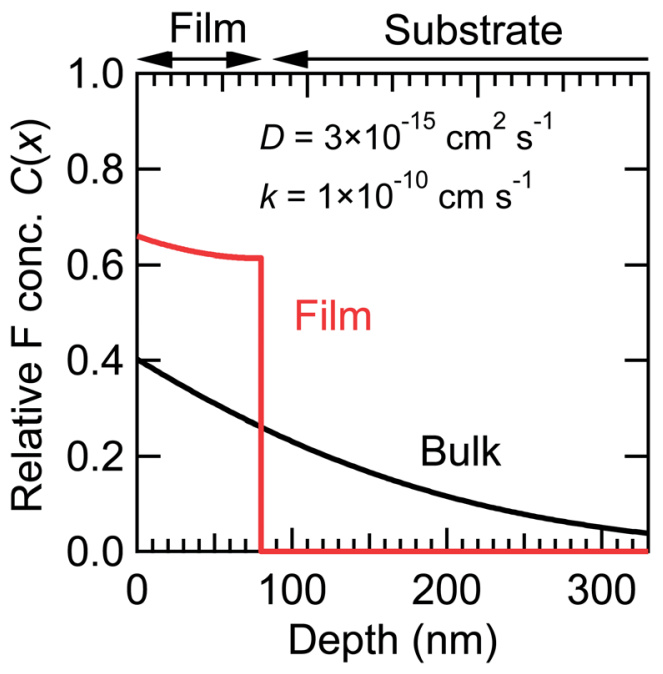

Fig. 10 Relative fluorine concentration $(C(x))$ vs. depth $(x)$ curves at $t=$ $24 \mathrm{~h}$, calculated for a thin film with $l=80 \mathrm{~nm}$ and for a bulk sample with $l \rightarrow \infty$. $D$ and $k$ were assumed to be $3 \times 10^{-15} \mathrm{~cm}^{2} \mathrm{~s}^{-1}$ and $1 \times$ $10^{-10} \mathrm{~cm} \mathrm{~s}^{-1}$, respectively.

$$
C(x)=1-\sum_{n=1}^{\infty} \frac{2 L \cos \left(\beta_{n} \frac{l-x}{l}\right) \exp \left(\frac{-\beta_{n}{ }^{2} D t}{l^{2}}\right)}{\left(-\beta_{n}{ }^{2}+L^{2}+L\right) \cos \beta_{n}} \quad(x \leq l)
$$

where $x$ is the distance from the surface, $t$ is the time, $D$ is the diffusion coefficient, $k$ is the surface exchange coefficient, $l$ is the thickness of the film, and $L=l k / D .^{23}$ The $\beta_{n}$ values are the positive roots of the equation: $\beta_{n} \tan \beta_{n}=L$. Approximately, the value of $D$ describes the overall shape of the $C(x)$ curve, while $k$ determines the $C(x)$ value at $x=0$. Fig. 10 shows the depth dependence of $C(x)$ for a thin film with $l=80 \mathrm{~nm}$, and for a bulk sample with $l \rightarrow \infty$ at $t=24 \mathrm{~h}$, where $D$ was set to $3 \times 10^{-15}$ $\mathrm{cm}^{2} \mathrm{~s}^{-1}$, so as to reproduce the fluorine depth profile measured by XPS (Fig. 5). In the case of the bulk sample, $C(x)$ decreases with $x$ in an exponential manner, with the diffusion length of 3 $\times 10^{2} \mathrm{~nm}$. That is, only fluorine diffuses into the surface regions, which means that the higher fluorine contents experimentally observed in thin films are attributable to smaller grain sizes, representing the maximum length of the diffusion path.

\section{Conclusions}

We have reported the successful synthesis of $\mathrm{SrFeO}_{3-x} \mathrm{~F}_{x}$ epitaxial thin films on STO substrates via topotactic fluorination of $\mathrm{SrFeO}_{3-\delta}$ precursor films using PVDF. The $\mathrm{SrFeO}_{3-x} \mathrm{~F}_{x}$ thin films were obtained at a lower temperature than polycrystalline bulk samples. Furthermore, the fluorine content $(x)$ in the $\mathrm{SrFeO}_{3-x} \mathrm{~F}_{x}$ films was controllable by adjusting the fluorination temperature and/or the amount of oxygen vacancies in the precursor film. The higher fluorination reactivity in the $\mathrm{SrFeO}_{3-\delta}$ precursor film, compared with that observed in bulk samples, can be rationalized by taking smaller grain sizes, being the maximum length of the diffusion path, into account within the framework of the fluorine-diffusion model via oxygen vacancy.

\section{Acknowledgements}

We thank Prof. Kimikazu Sasa, Mr Satoshi Ishii, Dr Hiroshi Naramoto, and Dr Daiichiro Sekiba of University of Tsukuba, and Prof. Katsuyuki Fukutani of the University of Tokyo for their assistance with the NRA measurements. This work was partially supported by the Murata Science Foundation, and the Nippon Sheet Glass Foundation for Materials Science and Engineering. The EDS measurements were conducted in the Research Hub for Advanced Nano Characterization, the University of Tokyo, supported by the Ministry of Education, Culture, Sports, Science and Technology (MEXT), Japan.

\section{Notes and references}

1 M. Al-Mamouri, P. P. Edwards, C. Greaves and M. Slaski, Nature, 1994, 369, 382.

2 M. Sturza, H. Kabbour, S. Daviero-Minaud, D. Filimonov, K. Pokholok, N. Tiercelin, F. Porcher, L. Aldon and O. Mentré, J. Am. Chem. Soc., 2011, 133, 10901.

3 P. R. Slater, J. Fluorine Chem., 2002, 117, 43.

4 Y. Kobayashi, M. Tian, M. Eguchi and T. E. Mallouk, J. Am. Chem. Soc., 2009, 131, 9849.

5 F. J. Berry, R. Heap, Ö. Helgason, E. A. Moore, S. Shim, P. R. Slater and M. F. Thomas, J. Phys.: Condens. Matter, 2008, 20, 215207.

6 F. J. Berry, F. C. Coomer, C. Hancock, Ö. Helgason, E. A. Moore, P. R. Slater, A. J. Wright and M. F. Thomas, J. Solid State Chem., 2011, 184, 1361.

7 F. J. Berry, X. Ren, R. Heap, P. Slater and M. F. Thomas, Solid State Commun., 2005, 134, 621.

8 R. Heap, P. R. Slater, F. J. Berry, O. Helgason and A. J. Wright, Solid State Commun., 2007, 141, 467.

9 Ö. Helgason, Hyperfine Interact., 2008, 184, 143.

10 O. Clemens, M. Kuhn and R. Haberkorn, J. Solid State Chem., 2011, 184, 2870.

11 F. J. Berry, A. F. Bowfield, F. C. Coomer, S. D. Jackson, E. A. Moore, P. R. Slater, M. F. Thomas, A. J. Wright and X. Ren, J. Phys.: Condens. Matter, 2009, 21, 256001.

12 F. J. Berry, X. Ren, R. Heap, P. Slater and M. F. Thomas, J. Phys. Chem. Solids, 2008, 69, 2032.

13 C. A. Hancock, T. Herranz, J. F. Marco, F. J. Berry and P. R. Slater, J. Solid State Chem., 2012, 186, 195.

14 E. J. Moon, Y. Xie, E. D. Laird, D. J. Keavney, C. Y. Li and S. J. May, J. Am. Chem. Soc., 2014, 136, 2224.

15 C. K. Blakely, J. D. Davis, S. R. Bruno, S. K. Kraemer, M. Zhu, X. Ke, W. Bi, E. E. Alp and V. V. Poltavets, J. Fluorine Chem., 2014, 159, 8.

16 S. Inoue, M. Kawai, Y. Shimakawa, M. Mizumaki, N. Kawamura, T. Watanabe, Y. Tsujimoto, H. Kageyama and K. Yoshimura, Appl. Phys. Lett., 2008, 92, 161911.

17 I. D. Brown and D. Altermatt, Acta Crystallogr., Sect. B: Struct. Crystallogr. Cryst. Chem., 1985, 41, 244.

18 D. Drouin, A. R. Couture, D. Joly, X. Tastet, V. Aimez and R. Gauvin, Scanning, 2007, 29, 92.

19 H. Wadati, D. Kobayashi, H. Kumigashira, K. Okazaki, T. Mizokawa, A. Fujimori, K. Horiba, M. Oshima, 
N. Hamada, M. Lippmaa, M. Kawasaki and H. Koinuma, Phys. Rev. B: Condens. Matter Mater. Phys., 2005, 71, 035108.

20 T. Yamashita and P. Hayes, Appl. Surf. Sci., 2008, 254, 2441.

21 A. Chikamatsu, T. Matsuyama, Y. Hirose, H. Kumigashira, M. Oshima and T. Hasegawa, J. Electron Spectrosc. Relat. Phenom., 2012, 184, 547.
22 H. Yamada, M. Kawasaki and Y. Tokura, Appl. Phys. Lett., 2002, 80, 622.

23 E. Fischer, L. Joshua and J. L. Hertz, Solid State Ionics, 2012, 218, 18. 